\title{
NUMERICAL MODEL OF THREE STAGE SPRAY DRYING FOR ZEOLITE 4A - WATER SUSPENSIONS COUPLED WITH A CFD FLOW FIELD
}

\author{
Gomboc, T. ${ }^{*}$ Z Zadravec, M. ; Ilijaz, J. ; Sagadin, G. ${ }^{* *} \&$ Hribersek, M. \\ * University of Maribor, Faculty of Mechanical Engineering, Smetanova 17, SI-2000 Maribor, Slovenia \\ ${ }^{* *}$ Silkem, d.o.o., Tovarniska cesta 10, SI-2325 Kidricevo, Slovenia \\ E-Mail: timi.gomboc@um.si,matej.zadravec@um.si,jurij.iljaz@um.si,gregor.sagadin@silkem.si, \\ matjaz.hribersek@um.si
}

\begin{abstract}
In the present work, a detailed description of a three-stage spray drying model capable of accurate simulation of drying of zeolite suspensions coupled with a CFD flow solver is presented. The models resolve the temperature field in the interior of the droplet, which consists of zeolite particles with adsorbed water and liquid water in the porous channels between the particles. The diffusion process in the interior of the particle is described by the Stefan diffusion model in the dried outer region, and the temperature field is accounted for by the unsteady state heat conduction model with a phase transition at the interface of the wet core. A new approach to the specification of the effective porosity of the dried crust is proposed, where a linear variation of the effective porosity with respect to radial position is applied. The correctness of the model is tested on the drying conditions, determined by the CFD computation, of droplets of different size in a pilot scale spray dryer. The computational results show, that the developed model presents an important upgrade to the single stage spray drying model, as used in the majority of multiphase CFD codes.

(Received in September 2018, accepted in March 2019. This paper was with the authors 2 months for 1 revision.)
\end{abstract}

Key Words: Heat and Mass Transfer, Spray Drying, Multistage Drying, Particle Transport, Zeolite 4A, Computational Fluid Dynamics

\section{INTRODUCTION}

Prediction of drying characteristics in spray drying is nowadays still a vivid research field in process industries. Significant advances were already made in the development of modern computational tools for spray drying. They range from development of dedicated spray drying models that account for transport phenomena at the particle level and typically work with predefined standard drying conditions, to the multilevel drying models, combining resolution of the particle kinetics with detailed resolution of the flow field by means of Computational Fluid Dynamics (CFD). As in spray dryers the particles are of sub millimetre size and residence times are typically only a few seconds, development of accurate numerical model to simulate particle drying presents a challenging task. Numerical modelling of such a process, where heat and mass transfer between each particle and the fluid is taken in account, presents a challenge from the computational point of view. In dependence of the spray dryer size, from hundred thousand to a few hundred thousand particles are typically present in the system, and need to be taken into account.

Zeolites are known for their sorption characteristics. As sorption is accompanied by the heat exchange with the surroundings, an accurate computational model should not neglect this effect. The numerical resolution of the interior of the drying droplet, consisting of numerous base zeolite crystals, is therefore necessary. The key thermodynamic variable is here the temperature and its change, as the sorption processes depend strongly on the variations of temperature. In the case of drying, desorption is the main process, as the thermodynamic conditions in the exterior of the particle (dryer chamber) are characterised by high 
temperatures and low values of water vapour partial pressures, both promoting release of adsorbed water from the zeolite structure. There exist several research works in the field of development of computational models for spray drying, ranging from a simplified drying kinetics model of Langrish and Kockel [1] to two-stage models for the simultaneous mass, heat and momentum transfer by Levi-Hevroni et al. [2]. Mezhericher et al. [3] extended the two-stage model with the solution of PDE-based models of temperature profiles within the particle, and Sadafi et al. [4] presented a four stage model, where the two additional stages we added to take into account the adjustment of the temperature at the start of the process as well as during the transition to formation of the rigid crust. In the case of zeolite particles drying, Sagadin et al. [5] presented a two-stage model with PDE-based calculation of temperature profile in the spherical particle, with the Stefan diffusion model for the mass transfer rate in the dry crust of the particle.

Because the porous material is used, one-stage drying models are not suitable. In this case the particle interior contains water, which in the one-stage drying models is not taken into account. This is the reason why the two- and three-stage drying models of spherical particles are more suitable for the implementation in the framework of the CFD when the porous material is taken in account. In the case of Lagrangian particle tracking [6-8], a droplet is numerically tracked through the solution domain by direct computation of heat, mass and momentum transfer with the continuous phase, which allows evaluation of drying gas conditions and particulate phase conditions within the drying chamber. Within the LagrangeEuler multiphase CFD models [6,9] the spray drying models typically account for only the first drying stage, and the resulting drying times are seldom realistic. Recently, Mezhericher et al. [10] implemented the advanced two stage spray drying models in the CFD framework.

The present work reports on further development of the two and three stage drying model, as implemented in Sagadin et al. [5,11], by adding a dedicated model for the evaluation of the changing cross sectional area of the dry crust of the zeolite 4A, Sagadin et al. [11], used in the computation of the second drying stage. By Sagadin et al. [11] one way coupled simulation was made, where only conditions from drying air was taken in account. The new developed particle drying model is two ways coupled to the CFD flow field. In addition, that the condition in drying air was considered, the sources from droplet to drying air are comprised. The test scenario deals with drying of a single droplet of different size in a pilot scale spray drier. In the coupled model the local temperature and water vapour concentration conditions in the fluid flow in the spray dryer are considered. The numerical model is composed of two codes: the finite difference code for the numerical solution of heat transfer through the droplet and the CFD finite volume method code for computation of flow conditions in the dryer. Both codes communicate in every time step and exchange current values of air temperature, particle relative velocity, air humidity, water vapour mass flow rate and heat used for moisture evaporation.

\section{PROBLEM DESCRIPTON}

The case under consideration is a counter-current spray drier equipped with spray nozzle, producing droplets with a size between 100 and 250 micrometres. The geometry of the model is sampled from the Anhydro LAB S1 spray dryer. The spray dryer (Fig. 1) is $1800 \mathrm{~mm}$ in height and consist of the cylindrical part with $760 \mathrm{~mm}$ height and diameter of $1000 \mathrm{~mm}$, connected to the $60^{\circ}$ conical part ending with the outlet. Air inlet at the top of dryer is positioned. In the middle of the dryer spray nozzle in opposite direction as air flow direction is positioned. Conical region with extended pipe represent the outlet. This configuration results in the first part of the droplet trajectory exposed to a counter-current flow of drying air, followed by a transition into the region of co-current flow of drying air. In order to avoid 
problems with outflow conditions specification, the outlet of the dryer is connected to the outlet tube, leading to the cyclone dust collector, which was not considered in the computational model.

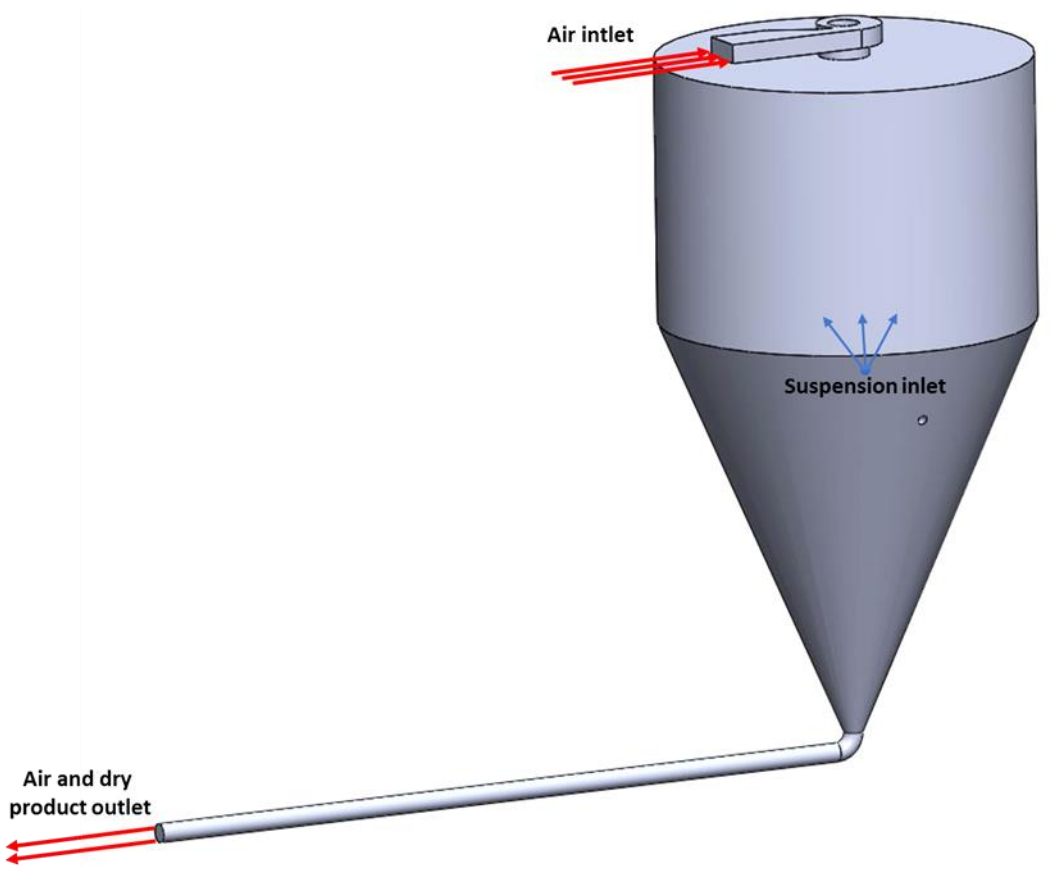

Figure 1: Laboratory spray dryer model with simplified drying air flow lines and nozzle position.

In Fig. 2 the three drying stages of a porous droplet is presented (part a). Dry porous particle contains between 45 to $50 \%$ void space, which is at the start of the drying occupied by the moisture.

a)

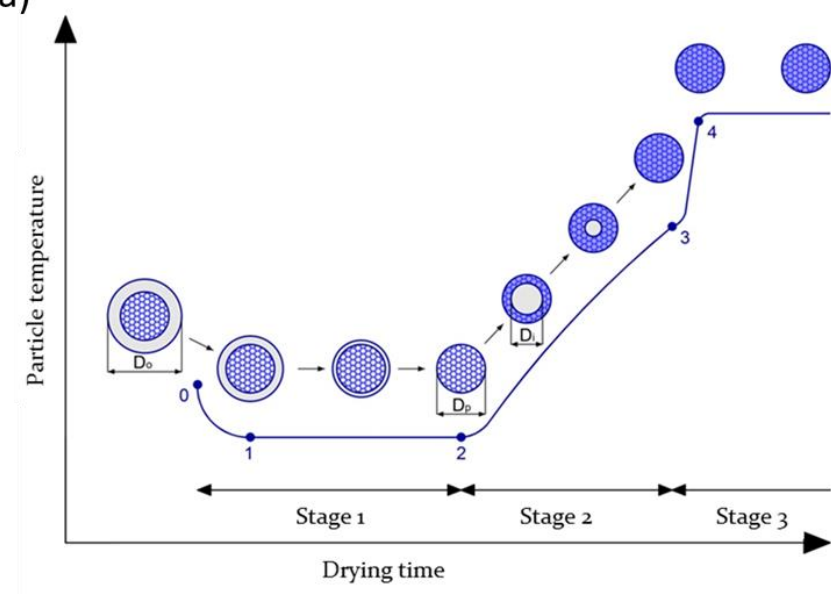

b)
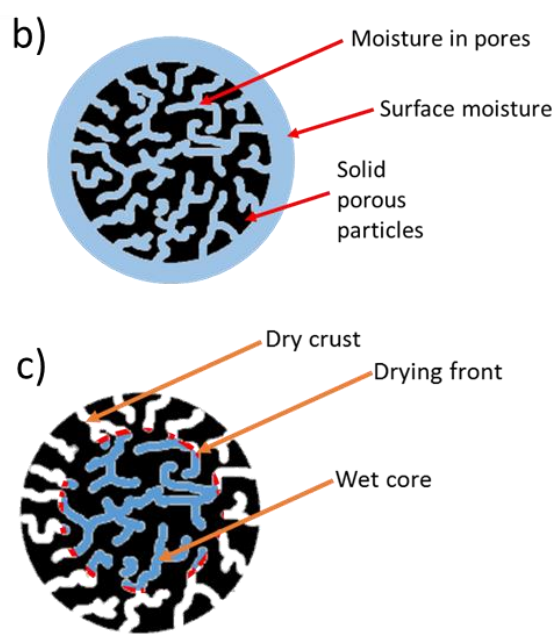

Figure 2: Drying stages of zeolite suspension droplets (a); droplet structure after leaving the nozzle (b); droplet structure in the second drying stage (c).

In the $1^{\text {st }}$ stage the surface moisture (Fig. 2, part b) is removed, by means of convective heat and mass transfer. In the second drying stage, the drying front, which separate dry crust (part of particle which is dry) and wet core (part of particle which is not yet dry) (Fig. 2, part b), is inside the porous particle, where the diffusion processes govern the drying process. After the moisture in the interior is removed (wet core size is equal 0 ) the remaining moisture is removed by the process of desorption, presenting the $3^{\text {rd }}$ drying stage. 
The coupled numerical model, used for computation of drying characteristics of zeolitewater suspension, consists of the CFD code Ansys CFX and an in-house developed finite difference method based Lagrangian particle tracking code. Particle as the sphere is modelled, where only temperature change in radial direction was calculated. Although the Finite Difference Method was used. The coupling is based on the use of dedicated user Fortran routines, with the general idea presented in Fig. 3. In the arrows main calculated values from each code are presented.
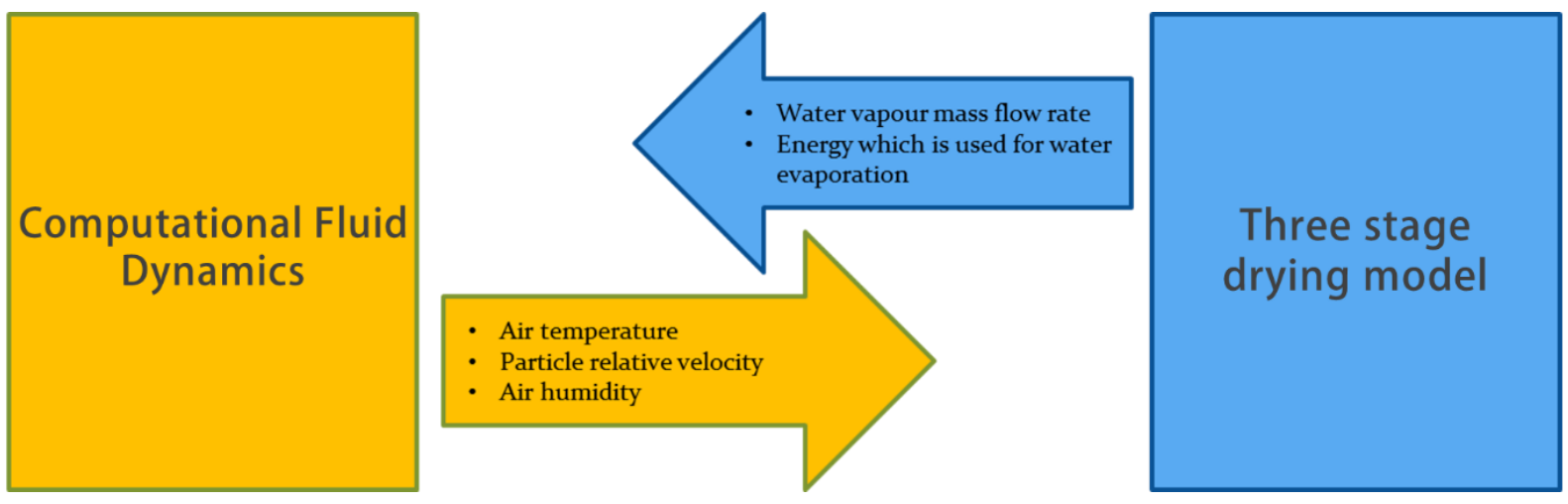

Figure 3: The two-way coupling model between the CFD part and three stage particle drying model.

\section{PARTICLE THREE STAGE DRYING MODEL}

The described stages of zeolite particle drying depend strongly on the conditions in the vicinity of a particle. As the particle travels through the interior of the dryer, the drying conditions near the particle change. In order to develop a computational model for spray drying inside a typical counter-current spray dryer, computational models for drying air conditions and a separate model for heat and mass transfer in the dispersed phase were developed, with the latter model based on the two stage drying model of [3] and [12]. In the following, a detailed explanation of derivation of the three stage drying model is presented.

The process of drying is initiated when the partial pressure of water vapour at the surface of the particle exceeds the partial water vapour pressure in the drying medium. In the drying stage 1 the evaporation at the outer diameter of the spherical particle takes place. The evaporated water mass flow $\dot{m}_{v}$ from the surface of the radius $R_{d}$ and the heat exchange with the drying air are:

$$
\begin{gathered}
\dot{m}_{v}=h_{D}\left(\rho_{v, s}-\rho_{v, \infty}\right) 4 \pi R_{d}^{2}, \\
c_{p, d} m_{d} \frac{\partial T_{d}}{\partial t}=h\left(T_{g}-T_{d}\right) 4 \pi R_{d}^{2}-h_{f g} \dot{m_{v},}
\end{gathered}
$$

with the Ranz-Marshall correlation for a sphere used for evaluation of the convective heat and mass transfer coefficients [11]. $\rho_{v, s}$ and $\rho_{v, \infty}$ in above equations represent the difference between a local density of water vapour on particle surface and a density of water vapour away in surrounding gas, $h_{D}$ is mass transfer coefficient, $h$ is heat transfer coefficient, $c_{p, d}$ is droplet specific heat, $m_{d}$ is droplet mass, $h_{f g}$ is specific heat of evaporation and $T_{g}$ is temperature. In equations subscript $d$ represents droplet, $g$ gas, $v$ vapour and $w$ water. The evaporation of water results in the decrease of the particle radius, computed by the equation:

$$
\frac{\partial R_{d}}{\partial t}=-\frac{1}{\rho_{d, w} 4 \pi R_{d}^{2}} \dot{m_{v}}
$$

At the end of the time step the particle moisture content is updated. If the calculated moisture is higher than the critical particle moisture value, the calculation of the first drying 
stage resumes. It has to be noted that the critical particle moisture is a material property and has to be experimentally determined before the start of the numerical simulations.

In the second drying stage the drying front (interface) is moved inside the particle, where by considering the diffusion process governing the mass transfer inside the porous crust the Stefan model for one sided diffusion is applied:

$$
\dot{m}_{v}=-\frac{8 \pi \varepsilon^{\beta} D_{v, c r} M_{w} p_{g}}{\kappa\left(T_{c r, s}+T_{w c, s}\right)} \frac{R_{p} R_{i}}{R_{p}-R_{i}} \ln \left[\frac{p_{g}-p_{v, i}}{p_{g}-\left(\frac{\kappa}{4 \pi M_{w} h_{d} R_{p}^{2}} \dot{m}_{v}+\frac{p_{v, \infty}}{T_{g}}\right) T_{p, s}}\right]
$$

where $p_{g}, p_{v, i}$ and $p_{v, \infty}$ represent the drying air pressure and partial water vapour pressures at the interface of wet core and in the surrounding drying air, respectively. In the model $\varepsilon$ is the porosity of the dry crust, consisting of a system of zeolite particles, and $\beta$ the empirical constant, which determines the overall effective porosity of the dried crust. The crystal structure of the zeolite $4 \mathrm{~A}$ is characterized by an octagonal shape, therefore the effective cross sectional area is lower than in the case of spherical particles. A higher value of $\beta$ has to be used than for the case of a random porous cluster $(\beta=3$ as in [11]). In general, the increase in the value of $\beta$ causes a decrease in the evaporation rate. As the dried crust region thickness increases with drying time this leads to increase in mass transfer resistance. A similar effect has the influence of the adsorbed moisture, that remains in the crust crystals and which is desorbed with increasing the inner temperature of the drying particle. This desorption process, that is not covered by the implemented Stefan diffusion model, contributes to the local increase in water vapour partial pressure inside the porous channels, leading to an effective decrease of the driving force for the diffusion and hence evaporation rate. In order to account for this effect in the Stefan model of the second stage, the value of $\beta$ should increase with drying progress. In [13], a study was conducted on the determination of $\beta$ in drying of pharmaceutical porous granules. It was found out, that the value of $\beta$ decreases with increasing temperature of the drying gas. In our case, we extended this conclusion to the determination of the varying value of $\beta$ and a new approach to the specification of the effective porosity of the dried crust was developed, taking into account a linear dependence of the $\beta$ value with respect to the particle radius was set, and two values of $\beta$ were chosen. The lower one was set at the outer particle radius, where the temperature is closest to the high drying gas temperature, and the higher value was set on the radius of the current wet core interface with a lower value of temperature as in the drying gas. Based on extensive numerical tests, the values of 4.1 and 8.0 were selected as suitable in drying of zeolite/water suspension.

The water vapour saturation pressure $p_{s a t}$ at the interface is calculated with the Antoine model [14], where $A, B$ and $C$ are component specific constants (for water from 0 to $100^{\circ} \mathrm{C}$ is $A=8.07, B=1730.6$ and $C=233.43$ ), and corrected due to capillarity effect as:

$$
p_{v, i}=p_{s a t} \exp \left(\frac{-2 \sigma}{r \rho_{d, w} R_{v} T}\right)
$$

where $p_{v, i}$ represent pressure of water vapour at interface position, $p_{s a t}$ pressure of saturation and $\sigma$ is a nondimensional coefficient based on the ratio of the porous channel dimension and size of a diffusing molecule.

The mass flux of evaporated water calculation is done in an iterative process. With convergence criteria (relative error of 1e-6) achieved the new interface radius of the wet core is determined from the modified mass conservation equation:

$$
\frac{\partial R_{i}}{\partial t}=-\frac{1}{\varepsilon \rho_{d, w} 4 \pi\left(R_{d}\right)^{2}} \dot{m}_{v}
$$


In the second stage the outer diameter of the particle remains constant, however, since the drying front moves inside the particle, this leads to the decrease of the radius of the interface, where the drying front is located. The energy conservation in the second drying stage has to be computed separately for the wet core:

$$
\rho_{w c} c_{p, w c} \frac{\partial T_{w c}}{\partial t}=\frac{1}{r^{2}} \frac{\partial}{\partial r}\left(k_{w c} r^{2} \frac{\partial T_{w c}}{\partial r}\right), 0 \leq r \leq R_{i}(t)
$$

and for the dry crust region:

$$
\frac{\partial T_{c r}}{\partial t}=k_{c r} \frac{\partial}{\partial r}\left(\frac{\partial T_{c r}}{\partial r}\right), R_{i}(t) \leq r \leq R_{p}
$$

where $k$ represents thermal conductivity, $R_{i}$ represents interface radius and with subscripts $w c$ and $c r$ wet core and dry crust are labelled.

Both equations are coupled by the Stefan moving phase change boundary conditions [11]. The equation of energy conservation is solved by applying the Finite Difference Method, with central differencing scheme. The interior numerical grid consists of 9 nodal points, which position is recalculated at each time step [11] according to the relocation of the drying front.

The third drying stage considers removing of the remaining moisture, adsorbed in the zeolite particles. Although the main part of the particle moisture is already removed, the remaining adsorbed moisture can still be removed, as the particle continues to receive heat from the surroundings and the temperature is further increased, influencing the equilibrium conditions for the water adsorbed in the zeolite. If the temperature increases, the equilibrium amount of water in zeolite is decreased, and the excess water is evaporated into the surrounding drying gas. In order to avoid computation of the interior mass sources and consequent mass diffusion through the particle, which would further increase the computational cost of the multi-stage drying model, it is assumed, that the almost dry particle interior presents a negligible mass transfer resistance and the total amount of water, desorbed from the particle, is directly transported to the particle outer surface. In order to compute the heat energy conservation equation for the third stage, the desorbed mass flow of the third stage is calculated as:

$$
\dot{m}_{v}=G \frac{\left(T_{d}^{j+1}-T_{d}^{j}\right)}{\Delta t} \frac{\left(X_{c r}-X_{d}^{j}\right)}{X_{c r}} m_{d, s},
$$

with $X_{c r}$ the critical moisture content at the end of the second drying stage. $\Delta t$ represents time step and subscript $s$ represents dry matter in droplet. The gradient $\mathrm{G}$ is determined from the thermogravimetric data [11], and reads as:

$$
G=\frac{\Delta X_{p}}{\Delta T_{d}}=\frac{X_{p, i}-X_{p, i+1}}{T_{d, i}-T_{d, i+1}},
$$

where $X_{p, i}$ is the equilibrium moisture content at temperature $T_{d, i}$ and $X_{p, i+1}$ at temperature $T_{d, i+1}$.

\section{CFD MODEL AND COUPLING WITH THE PARTICLE MODEL}

\subsection{Coupled CFD - three stage drying model}

The CFD model solves the Reynolds averaged Navier-Stokes equations, which consist of: system mass conservation, momentum conservation, enthalpy conservation and water vapour mass conservation. As governing equations, the following set of equations was selected, including mass conservation, momentum conservation, energy equation and species conservation equation: 


$$
\begin{gathered}
\vec{\nabla} \cdot \vec{v}=0 \\
\frac{D \vec{v}}{D t}=\vec{g}-\frac{1}{\rho_{0}} \vec{\nabla} p+\vec{\nabla}\left(v_{e} \vec{\nabla} \vec{v}\right) \\
\frac{D T_{g}}{D t}=\vec{\nabla}\left(a_{e} \vec{\nabla} T_{g}\right)-I_{T} \\
\frac{D C_{g}}{D T_{g}}=\vec{\nabla}\left(D_{e} \vec{\nabla} C_{g}\right)+I_{c}
\end{gathered}
$$

With the relation between the water vapour concentration and the air moisture content $X_{g}$,

$$
C_{v}=\rho_{v} \frac{X_{g}}{1+X_{g}}
$$

the partial water vapour pressure can be computed. Hence, there exist a direct connection between the conditions of the drying air (velocity, vapour pressure, temperature) and the state of the drying particle, which enable the use of changing boundary conditions along each particle trajectory. Due to high inlet velocities and complex interior geometry of the dryer flow inside a spray dryer chamber is always turbulent. As a steady state operation of the spray dryer was assumed, the Reynolds Averaged Navier Stokes equation (RANS) turbulent models could be used. In the context of the RANS the eddy viscosity based SST transport model [15] was used. The Lagrangian particle tracking model $[7,16]$, was used for the discretization of the dispersed phase, and a two-way coupling between the fluid flow and the dispersed phase was implemented. In the case of the modelled pilot dryer, the drying regime (concurrent, counter current) can vary along trajectory, because local conditions are used (conditions at the currently particle position). The source terms $I_{T}$ and $I_{C}$ correspond to the heat and mass exchange between the particle and drying air, and are derived from computation of $Q$ and $m_{v}$. In every time step the mass flow of evaporated water is added as source in species conservation equation and energy used for water evaporation as energy sink in energy conservation equation. The overall coupling of the particle solver and the CFD solver is presented in Fig. 4. In every time step the exchange of information from CFD about drying air temperature, drying air humidity and droplet relative velocity at particle position is done and on the other side the particle drying is computed returning the value of water vapour mass flow and energy source to the CFD code.

Analysis of grid sensitivity for the CFD model was performed based on the Richardson extrapolation, and unstructured grids with $0.7,1.8$ and 4.8 million elements were tested. Based on this analysis, the 4.8 million grid was selected for all numerical computations. Transient numerical simulation was running at Intel Core i9-7900X CPU @ 3.30GHz. Time step was set at $0.01 \mathrm{~s}$ and parallel simulation was done on 10 cores. For five second numerical simulation of flow field in spray dryer was used 5.7 hours CPU. The inlet turbulence intensity was estimated at $5 \%$ and scalable wall functions were used [11].

\section{COMPUTATIONAL EXAMPLE AND RESULTS}

\subsection{Computational example}

The geometrical model consisted of the hot air inlet through the circular air distributor on top of the dryer, the main drying chamber consisting of cylindrical and conical part, the outlet pipe from the drying chamber as well as the inlet pipe for the high-pressure nozzle. The atomization was modelled using point particle source, where the injection angle at $20^{\circ}$ was set, as shown in Fig. 5. As we can see in Fig. 5, right, in the upper part of the spray dryer there exists a strong mixing region, which serves as the main drying part of the device. 


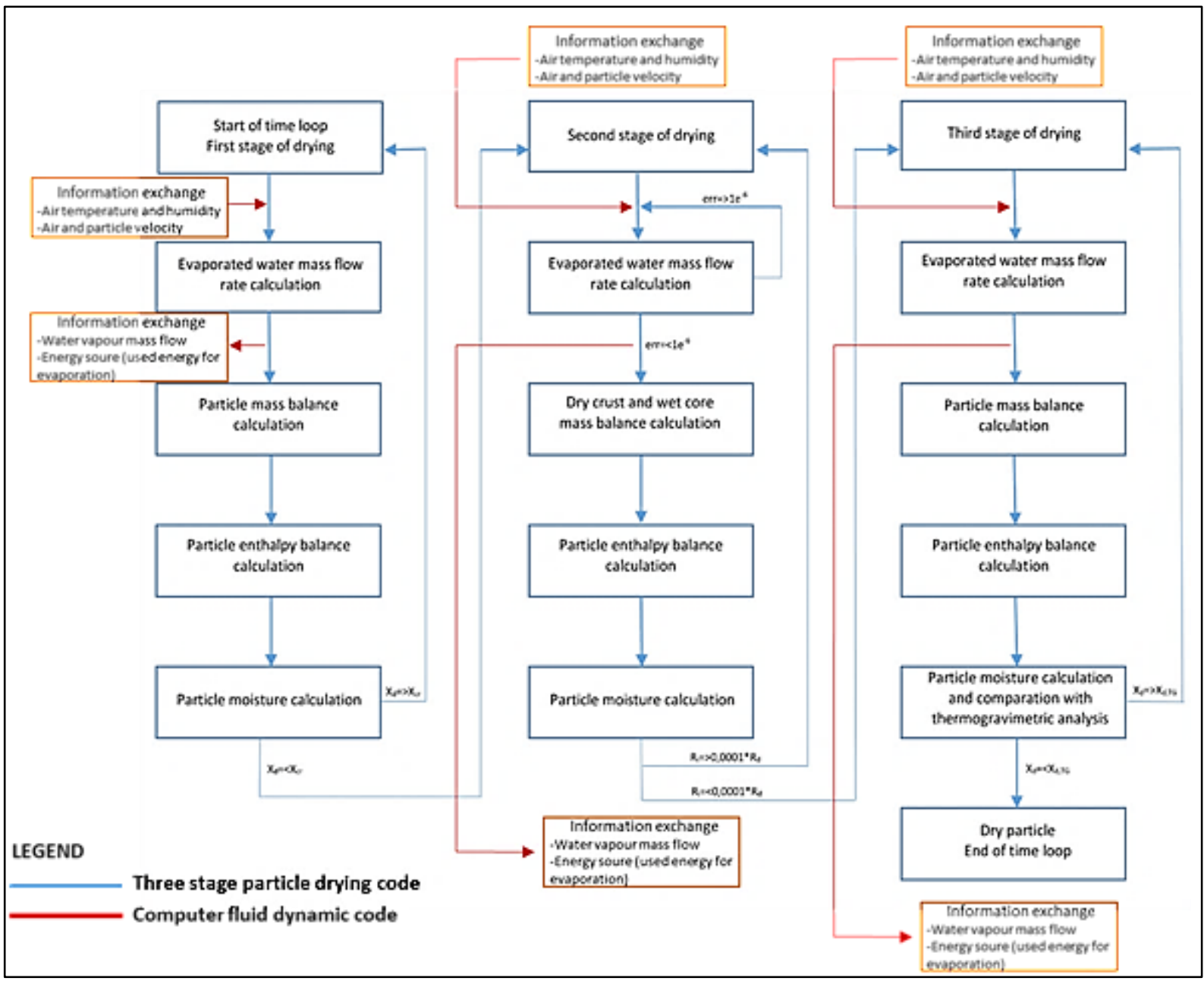

Figure 4: Coupled three stage particle drying calculation scheme with calculation steps.

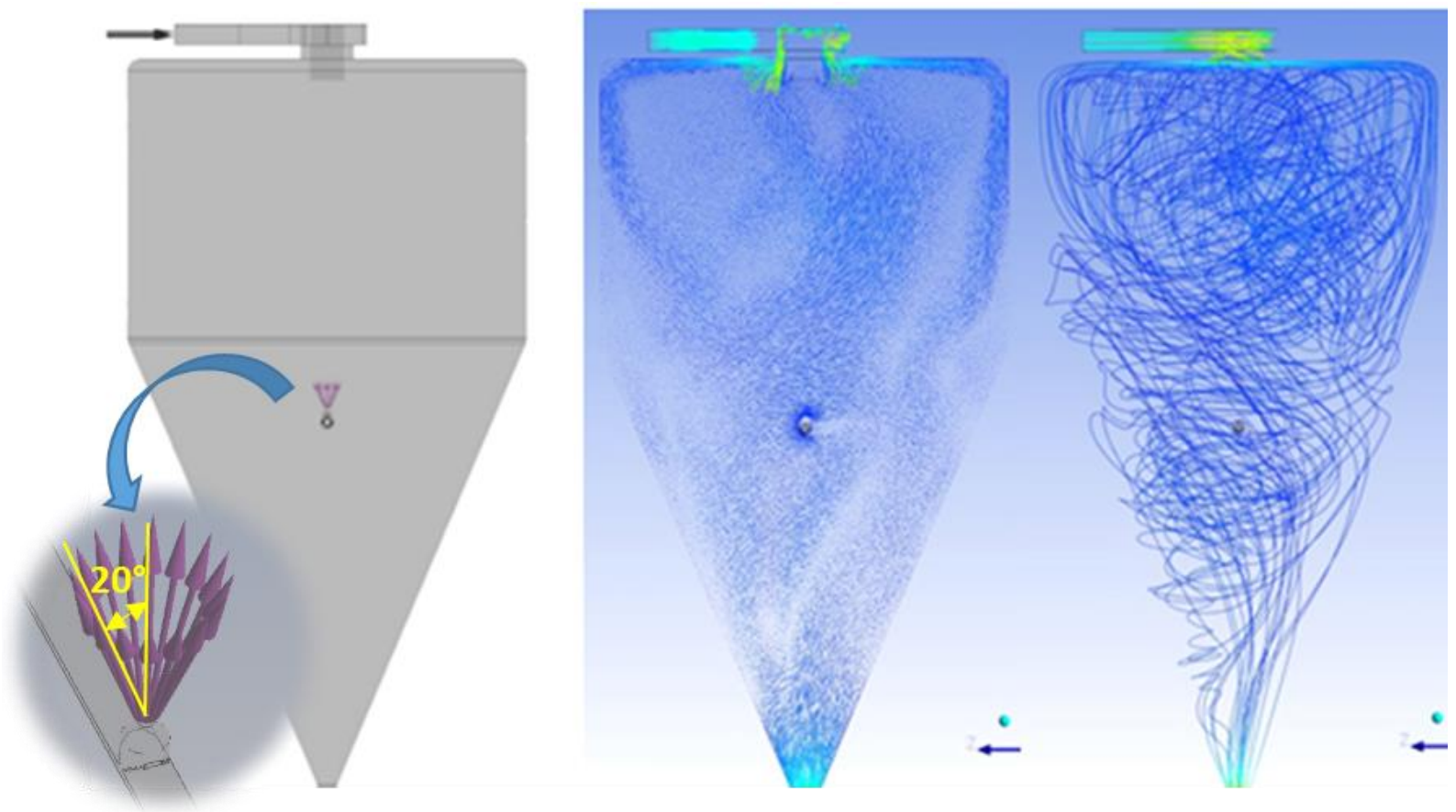

Figure 5: The particles inlet region (left); the velocity field with vectors (in the middle); the flow stream lines (right). 
The drying gas temperature at the inlet of the spray dryer was set at $150^{\circ} \mathrm{C}$. Initial absolute air humidity was set at 0.01 and air mass flow rate was set at $0.03 \mathrm{~kg} / \mathrm{s}$. The suspension droplets, formed by a spray nozzle, had the initial temperature of $25^{\circ} \mathrm{C}$ and moisture content of 1.25 . The outside temperature was set at the $25^{\circ} \mathrm{C}$ and the heat transfer coefficient was $0.5 \mathrm{~W} / \mathrm{m}^{2} \mathrm{~K}$.

\subsection{Particle drying results}

Because the conditions inside the spray dryer are characterized by a strong mixing, particles with different properties can follow different trajectories through the spray dryer. Boundary conditions for drying of the particles vary along the trajectory, as the particle relative velocity and the drying gas temperature along different trajectories vary. This can be best represented by calculating the Nusselt number along a particle trajectory for particles of different sizes, originating from the same inlet position, which is presented in Fig. 6. The difference is the most visible in the initial part of particle drying, when the particle is in the top part of the spray dryer, where the particle - fluid field interaction is the strongest. As the particle diameter changes, this gives rise to a change in the drag force, influencing the velocity and hence the trajectory of the particle. It is also evident, that the smaller particles, that follow the fluid flow more closely than larger ones, exhibit lower values of the Nusselt number.

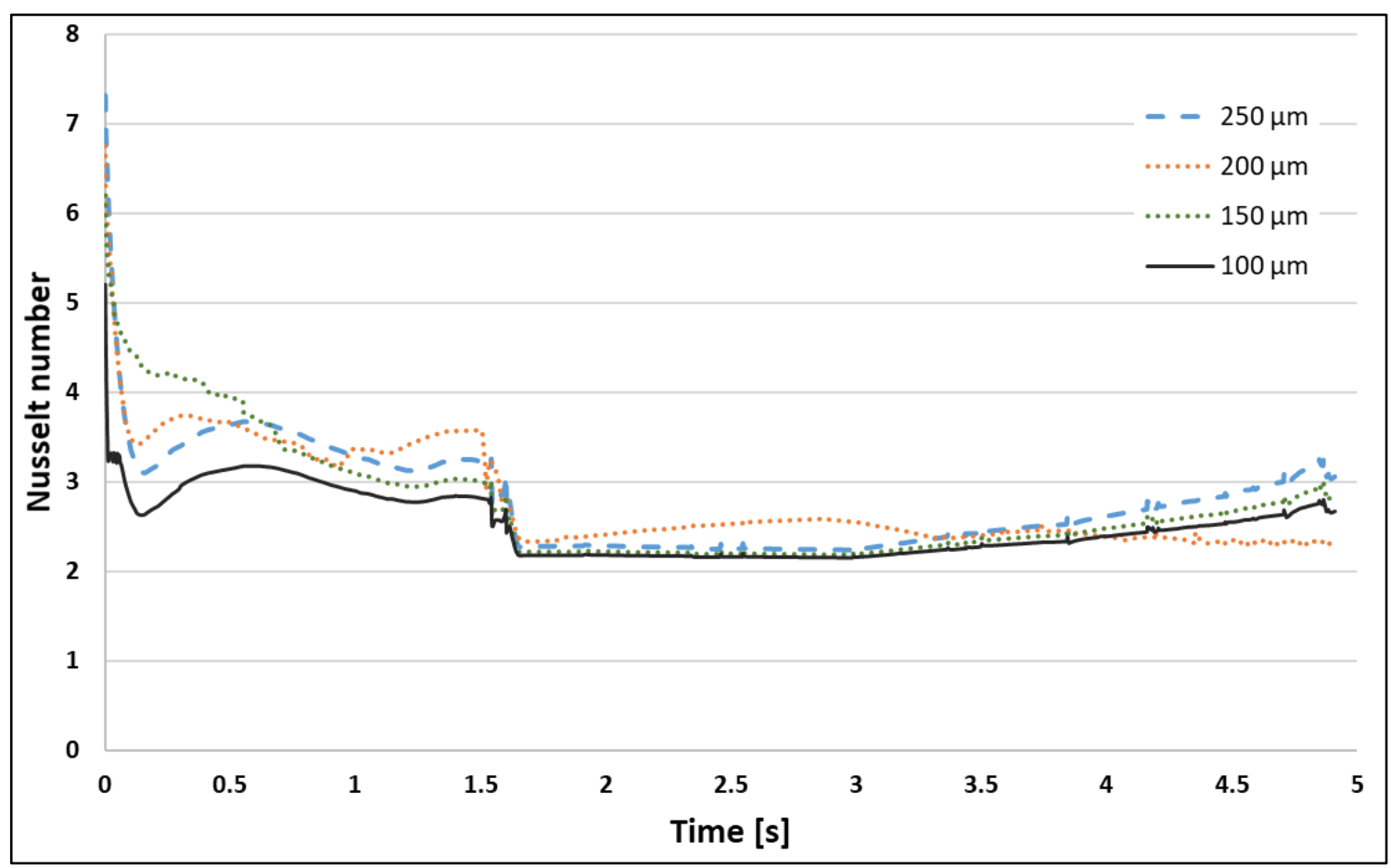

Figure 6: Nusselt number values for zeolite particles of different sizes along a typical trajectory.

As described in Section 3, drying of zeolite particles undergo three stages. In the first stage of the drying the particles surface moisture is removed. Since in this stage the drying interface and the particle outer radius coincide, the drying process leads to a decrease of the particle radius in first drying stage. After the first drying stage the particle outer radius is fixed, however the drying of the interior moisture gives rise to further movement of the interface, which now separates the dry crust and the wet core. At the drying interface position, the evaporation of water is taking place, and the interface position moves through the whole second drying stage with finally decreasing to zero, which means (when the interface radius is equal zero) that the particle interior is dry and the second drying stage is finished. Fig. 7 presents temporal evolution of the interface radius through the first drying stage (dotted line) 
and the second drying stage (hatched line). After the second drying stage, the process of desorption becomes the main mechanism of drying, which characterises the $3^{\text {rd }}$ stage of drying, where there is not any change of particles radius or interface radius.

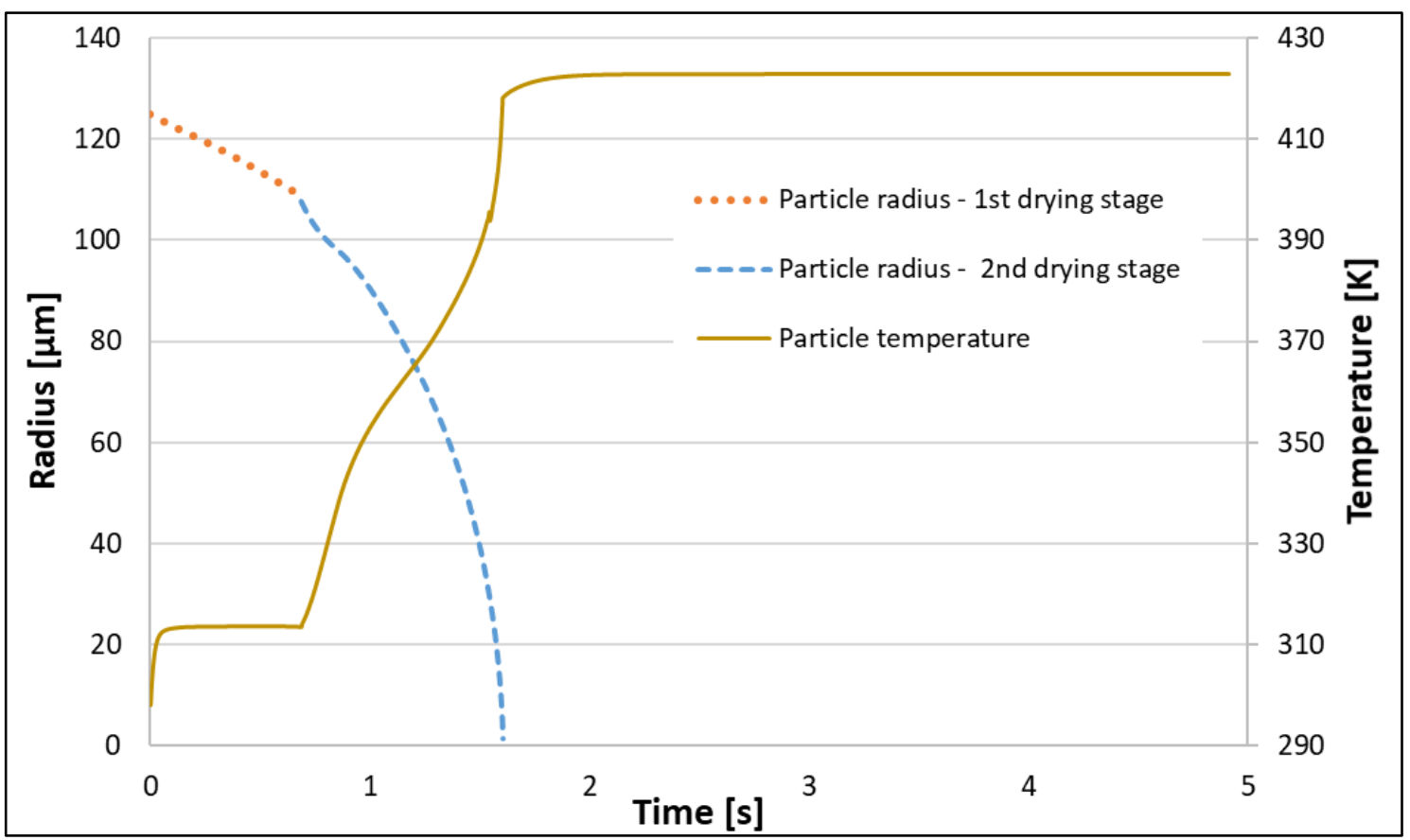

Figure 7: Particles temperature and particles radius through the $1^{\text {st }}$ and $2^{\text {nd }}$ drying stage for $250 \mu \mathrm{m}$ particle.
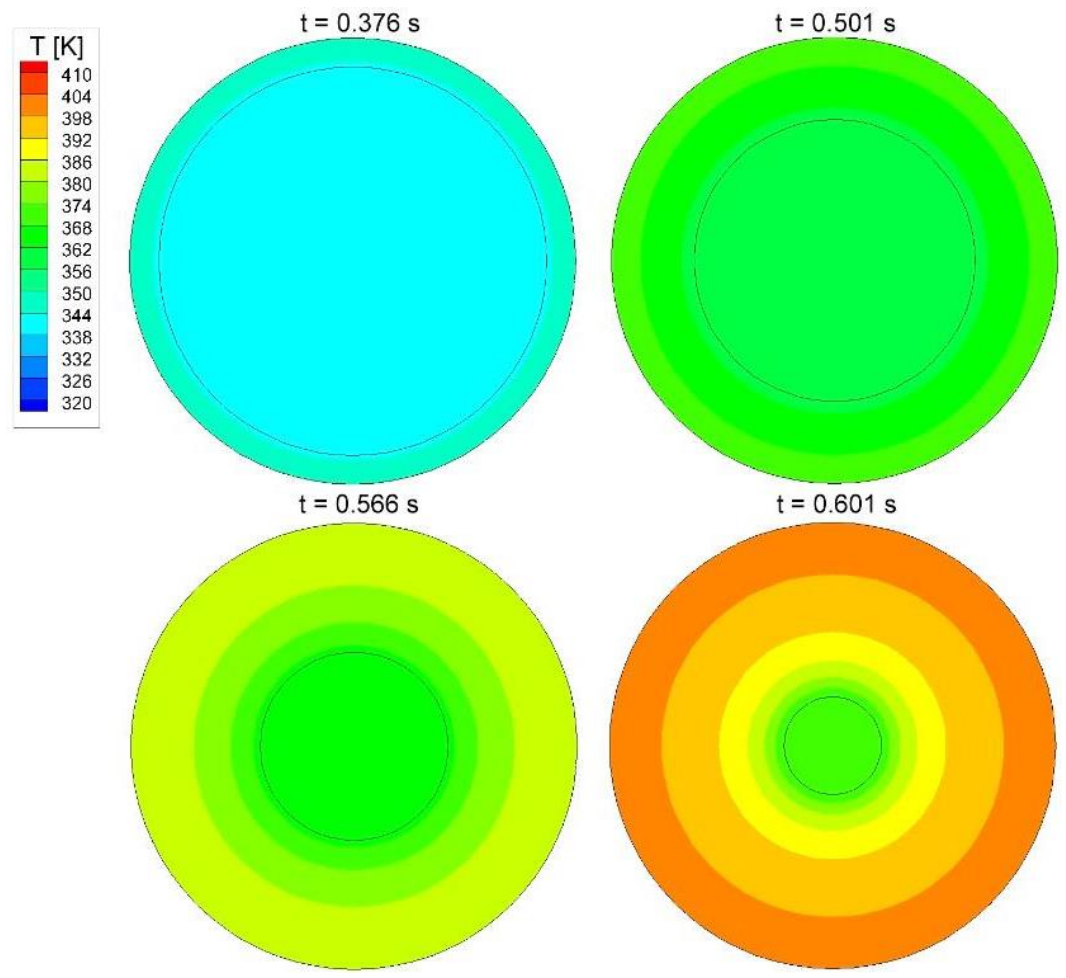

Figure 8: Temperature field inside the $150 \mu \mathrm{m}$ particle at different times in the second drying stage. The solid line shows the drying front position.

Through the second drying stage the temperature field in the particles interior is affected due to the evaporation of the moisture at the drying front. The temperature in the outer dry 
part of the particle increases towards the drying air temperature. On the interface position we have a temperature jump, because the heat of evaporation on the interface position acts like a heat sink. At the end of the second drying stage, the particle temperature is almost equal to the drying air temperature. The particle temperature fields with interface position at different times through the second drying stage are presented in Fig. 8.

The total drying time can be set as the time when particle moisture reaches its equilibrium with the drying air. As the temperature of the drying air is constantly changing due to the heat losses to the surroundings of the dryer, theoretically the total drying time would be equal to the residence time of the particle in the system. However, practically, the stabilization of the moisture vs. time curve can serve as an accurate indicator for determination of the drying time for particles of varying sizes shown in Fig. 9. In general, the shortest drying phase is the first drying stage, because it is occurring on the particle surface with direct contact with the drying air. In the second drying stage the drying rate decreases, because evaporated moisture has to diffuse through the porous dry crust. It is also evident that the total drying time increase is not linearly dependent on the particle radius.

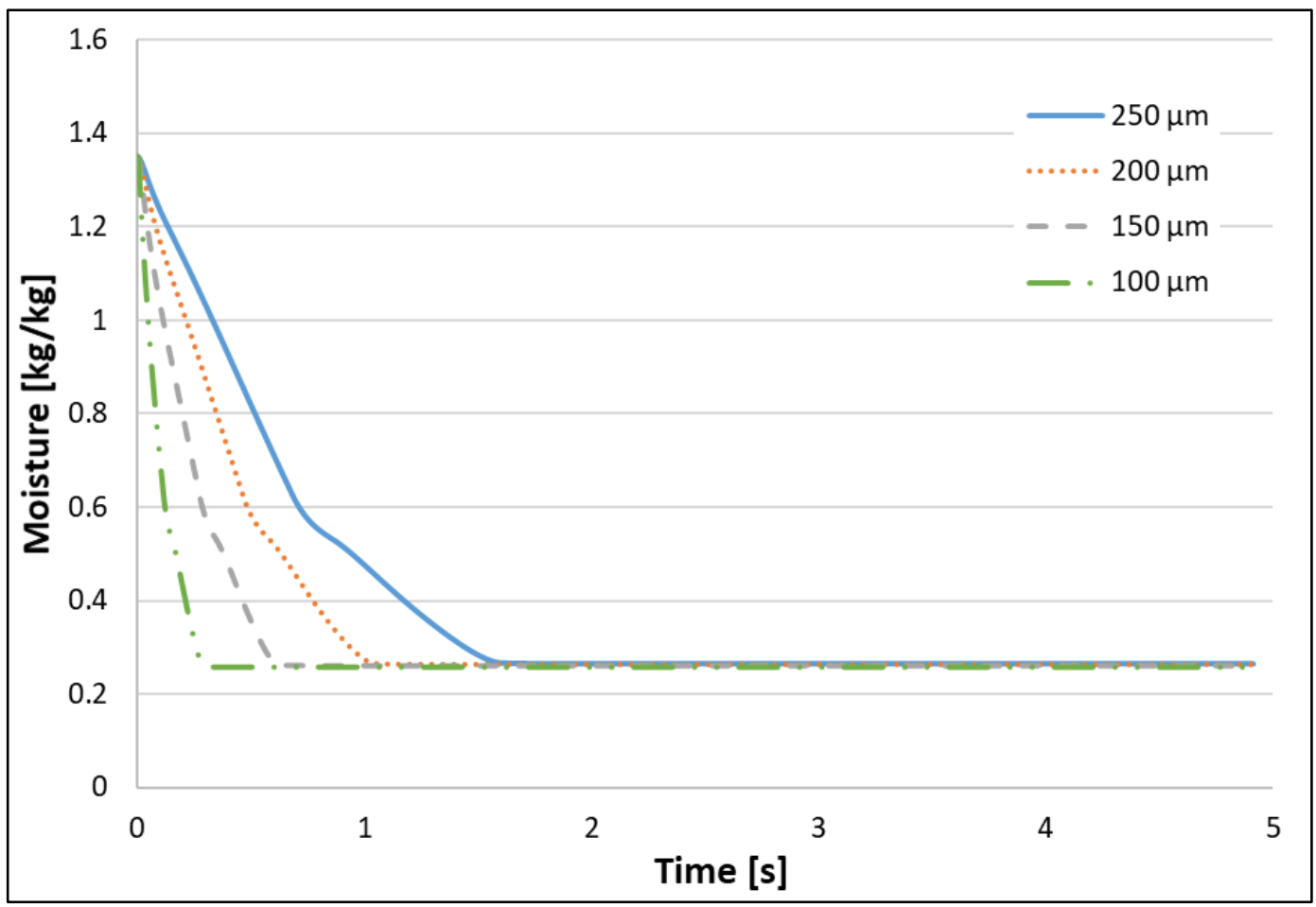

Figure 9: Particles moisture content through the drying process for different particle sizes.

\section{CONCLUSION}

In this paper a novel two-way coupled computational algorithm for the multi stage spray drying computation with CFD was developed, which builds on the three stage drying model for the dispersed particle phase coupled with heat and mass transport in RANS resolved fluid flow. The three stage particle drying model takes into account the heat and mass transfer resistance, of the dry part of the particle, when the drying front is located inside the particle. Additionally, the desorption characteristics of the zeolite 4A are taken into account by adding the third stage of drying, based on the thermogravimetry data. Contrary to the single stage spray drying models, in this way it is possible to account for a significant decrease in the drying rate in the last stages of the particle drying, and also account for desorption and adsorption phenomena of the porous particles, what additionally influences the overall drying 
rates. The direct coupling of the three stage spray drying model into the CFD leads to accurate data on particles trajectories and drying histories in the spray dryer and presents an excellent starting point for optimization of the drying procedures in a spray dryer.

\section{REFERENCES}

[1] Langrish, T. A. G.; Kockel, T. K. (2001). The assessment of a characteristical drying curve for milk powder for use in computationla fluid dynamics modelling, Chemical Engineering Journal, Vol. 84, No. 1, 69-74, doi:10.1016/S1385-8947(00)00384-3

[2] Levi-Hevroni, D.; Levy, A.; Borde, I. (1995). Mathematical modeling of drying of liquid/solid slurries in steady state one-dimensional flow, Drying Technology, Vol. 13, No. 5-7, 1187-1201, doi: $\underline{10.1080 / 07373939508917016}$

[3] Mezhericher, M.; Levy, A.; Borde, I. (2010). Theoretical drying model of single droplets containing insoluble or dissolved solids, Drying Technology, Vol. 25, No. 6, 1025-1032, doi: $\underline{10.1080 / 07373930701394902}$

[4] Sadafi, M. H.; Jahn, I.; Stilgoe, A. B.; Hooman, K. (2014). Theoretical and experimental studies on a solid containing water droplet, International Journal of Heat and Mass Transfer, Vol. 78, 25-33, doi:10.1016/j.ijheatmasstransfer.2014.06.064

[5] Sagadin, G.; Hribersek, M.; Skerget, L. (2014). Multiphase numerical model of spray drying of zeolite-water suspension, Proceedings of the $3^{\text {rd }}$ ThermaComp, 481-484

[6] Langrish, T. A. G. (2009). Multi-scale mathematical modelling of spray dryers, Journal of Food Engineering, Vol. 93, No. 2, 218-228, doi:10.1016/j.jfoodeng.2009.01.019

[7] Ravnik, J.; Hribersek, M.; Vogel, F.; Steinmann, P. (2014). Numerical simulation of particle movement in cellular flows under the influence of magnetic forces, International Journal of Simulation Modelling, Vol. 13, No. 3, 300-311, doi:10.2507/IJSIMM13(3)4.268

[8] Ravnik, J.; Skerget, L.; Hribersek, M.; Zunic, Z. (2008). Numerical simulation of dilute particle laden flows by wavelet BEM-FEM, Computer Methods in Appled Mechanics Engineering, Vol. 197, No. 6-8, 789-805, doi:10.1016/j.cma.2007.09.007

[9] Fletcher, D. F.; Guo, B.; Harvie, D. J. E.; Langrish, T. A. G.; Nijdam, J. J.; Williams, J. (2006). What is important in the simulation of spray dryer performance and how do current CFD models perform?, Applied Mathematical Modelling, Vol. 30, No. 11, 1281-1292, doi:10.1016/ j.apm.2006.03.006

[10] Mezhericher, M.; Levy, A.; Borde, I. (2010). Spray drying modelling based on advanced droplet drying kinetics, Chemical Engineering and Processing: Process Intensification, Vol. 49, No. 11, 1205-1213, doi:10.1016/j.cep.2010.09.002

[11] Sagadin, G.; Hribersek, M. (2017). A multistage spray drying model for zeolite 4A - water suspensions in a counter-current spray dryer, International Journal of Heat and Mass Transfer, Vol. 108, 1220-1228, doi:10.1016/j.ijheatmasstransfer.2016.12.107

[12] Mezhericher, M.; Levy, A.; Borde, I. (2008). Heat and mass transfer of single droplet/wet particle drying, Chemical Engineering Science, Vol. 63, No. 1, 12-23, doi:10.1016/j.ces.2007.08.052

[13] Mezhericher, M.; Levy, A.; Borde, I. (2011). Modelling the morphological evolution of nanosuspension droplet in constant-rate drying stage, Chemical Engineering Science, Vol. 66, No. 5, 884-896, doi:10.1016/j.ces.2010.11.028

[14] Cortes, F. B.; Chejne, F.; Carrasco-Marin, F.; Moreno-Castilla, C.; Perez-Cadenas, A. F. (2010). Water adsorption on zeolite $13 \mathrm{X}$ : comparison of the two methods based on mass spectrometry and thermogravimetry, Adsorption, Vol. 16, No. 3, 141-146, doi:10.1007/s10450-010-9206-5

[15] ANSYS, Inc. (2017). ANSYS Fluent Tutorial Guide, Release 18.0, ANSYS, Canonsburg, from http://users.abo.fi/rzevenho/ansys\%20fluent\%2018\%20tutorial\%20guide.pdf, accessed on 29-012019

[16] Ravnik, J.; Cernec, D.; Hribersek, M.; Zadravec, M. (2017). Magnetic susceptibility determination based on microparticles sedimentation analysis, International Journal of Simulation Modelling, Vol. 16, No. 2, 275-288, doi:10.2507/IJSIMM16(2)8.381 